\title{
Effect of carboxymethyl cellulose concentration on physical properties of biodegradable cassava starch-based films
}

\author{
Wirongrong Tongdeesoontorn' ${ }^{1}$ Lisa J Mauer ${ }^{2}$, Sasitorn Wongruong ${ }^{3}$, Pensiri Sriburi ${ }^{4}$, Pornchai Rachtanapun ${ }^{5,6^{*}}$
}

\begin{abstract}
Background: Cassava starch, the economically important agricultural commodity in Thailand, can readily be cast into films. However, the cassava starch film is brittle and weak, leading to inadequate mechanical properties. The properties of starch film can be improved by adding plasticizers and blending with the other biopolymers.

Results: Cassava starch (5\%w/v) based films plasticized with glycerol (30 g/100 g starch) were characterized with respect to the effect of carboxymethyl cellulose (CMC) concentrations (0, 10, 20, 30 and 40\%w/w total solid) and relative humidity (34 and 54\% $\mathrm{RH}$ ) on the mechanical properties of the films. Additionally, intermolecular interactions were determined by Fourier transform infrared spectroscopy (FT-IR), melting temperature by differential scanning calorimetry (DSC), and morphology by scanning electron microscopy (SEM). Water solubility of the films was also determined. Increasing concentration of CMC increased tensile strength, reduced elongation at break, and decreased water solubility of the blended films. FT-IR spectra indicated intermolecular interactions between cassava starch and CMC in blended films by shifting of carboxyl $(C=O)$ and $\mathrm{OH}$ groups. DSC thermograms and SEM micrographs confirmed homogeneity of cassava starch-CMC films.

Conclusion: The addition of CMC to the cassava starch films increased tensile strength and reduced elongation at break of the blended films. This was ascribed to the good interaction between cassava starch and CMC. Cassava starch-CMC composite films have the potential to replace conventional packaging, and the films developed in this work are suggested to be suitable for low moisture food and pharmaceutical products.
\end{abstract}

\section{Background}

The development of biopolymer-based edible films could replace the use of some petrochemicals in the food packaging industry and reduce the negative environmental impact associated with packages from nonrenewable and non-recyclable resources. Edible films are generally produced from renewable natural and abundant biodegradable polymeric materials such as polysaccharides, proteins, lipids, or the combination of these components. Some edible films and coatings have been widely used for fresh fruits, vegetables, confectioneries, frozen foods, and meat products [1]. However, many edible films have limitations in mechanical or barrier properties or are prohibitively expensive. Starch films

\footnotetext{
* Correspondence: p.rachta@chiangmai.ac.th

${ }^{5}$ Division of Packaging Technology, Faculty of Agro-Industry, Chiang Mai University, Chiang Mai 50100, Thailand

Full list of author information is available at the end of the article
}

often have good barrier properties to oxygen, carbon dioxide, and lipids and can protect products from lipid oxidation [2]. Films from polysaccharides are also stronger and more extensible than proteinaceous films [3].

Cassava (Manihot esculenta crantz) or tapioca is one of the economically important crops in Thailand and is the cheapest raw material for starch production. Structurally, cassava starch consists of $17 \%$ amylose content, and this is responsible for its strong film-forming characteristics [4]. Cassava starch can readily be cast into films. However, the cassava starch film is brittle and weak, leading to inadequate mechanical properties. Overcoming the brittleness of the film can be accomplished by adding plasticizers [5]. Common plasticizers used in the production of starch films are water, glycerol, sorbitol, and other low-molecular weight polyhydroxy compounds [6]. Glycerol and sorbitol are widely used as plasticizers because of their stability and 
edibility. The addition of plasticizers makes the brittle films more flexible, but also less strong [5] and results in higher moisture permeability [7]. This problem must be addressed to improve the functional properties of cassava starch films. Blending [8] or laminating [9] with other polysaccharide materials could improve cassava starch film mechanical functionality. Carboxymethyl cellulose (CMC), xanthan, guar, and arabic gum, which are water-soluble heteropolysaccharides with high molecular weights, are often used together with starches to provide desirable texture, control moisture and water mobility, and improve overall product quality and/or stability [10]. CMC is an anionic linear polysaccharide derived from cellulose. It is an important industrial polymer with a wide range of applications in flocculation, drug reduction, detergents, textiles, papers, foods, and drugs [11]. CMC is used primarily because it has high viscosity, is non-toxic, and is non-allergenic. The numerous hydroxyl and carboxylic groups in CMC enable water binding and moisture sorption properties. CMC hydrogel has a high water content, good biodegradability, and a wide range of applications due to its low cost [12]. Because of its polymeric structure and high molecular weight, it can be used as a filler in biocomposite films [13]. CMC is able to improve the mechanical and barrier properties of pea starch-based films [14].

Some edible films based on mixtures of multiple polysaccharides such as starch-methylcellulose [15], pullulan-starch [16], chitosan-starch and chitosan-pullulan [17], CMC-rice starch [10], and CMC-pea starch [14] have been investigated. These publications demonstrated that homogeneous structures containing a single-phase of polymeric complexes have been obtained. Depending on the interactions between components, these formulas can improve the mechanical and moisture barrier properties of the edible films in some cases. In a previous study [18], water vapor permeability and moisture sorption isotherms of cassava starch based films blended with $\mathrm{CMC}$ were studied. The addition of CMC to cassava starch films had no effect on the WVPs of all films tested (WVP ranged from 0.05 to 0.10 and 0.2 to $0.3 \mathrm{~g}$ $\mathrm{mm} /$ day $\mathrm{m}^{2} \mathrm{mmHg}$ at $33 \%$ and $54 \% \mathrm{RH}$, respectively), but moisture sorption of cassava starch based films increased with increasing CMC contents. It was suggested that the cassava starch based films with and without CMC had potential for use as biodegradable and edible packaging due to the moderate WVP. However, the mechanical properties of biodegradable films are also important for their applications. There is no data available about the physical properties of cassava starch films blended with CMC, thus the objective of this study was to determine the effect of CMC concentration on mechanical and physical properties of cassava starch based films.

\section{Results and discussion}

The influence of CMC concentrations on properties of cassava starch based films was analyzed in terms of FT-IR spectra, mechanical properties of the films, water solubility, DSC thermograms, and film morphology as reported below. All the cassava starch films with and without CMC appeared smooth, clear, and transparent. Film thickness ranged from 120-160 $\mu \mathrm{m}$.

The FT-IR spectrum of a cassava starch film (without $\mathrm{CMC}$ ) is shown in Figure 1a. A broad absorption band at 3268 is evident, due to the stretching frequency of the $-\mathrm{OH}$ group, and a band at $2920 \mathrm{~cm}^{-1}$ attributable to $\mathrm{C}-\mathrm{H}$ stretching vibration [11]. The presence of a strong absorption band at $1648 \mathrm{~cm}^{-1}$ confirms the presence of water. The bands around 1413 and $1337 \mathrm{~cm}^{-1}$ are assigned to $-\mathrm{CH}_{2}$ bending in plane and $\mathrm{C}-\mathrm{OH}$ bending vibration, respectively. The band at $1149 \mathrm{~cm}^{-1}$ is due to C-O-C antisymmetric bridge stretching [19].

The FT-IR spectrum of a CMC film is shown in Figure 1f. The broad absorption band at $3260 \mathrm{~cm}^{-1}$ is due to the stretching frequency of the - $\mathrm{COO}$ group [20] which overlaps with the - $\mathrm{OH}$ stretching region at 3480$3440 \mathrm{~cm}^{-1}$. The band at $2876 \mathrm{~cm}^{-1}$ is due to the $\mathrm{C}-\mathrm{H}$

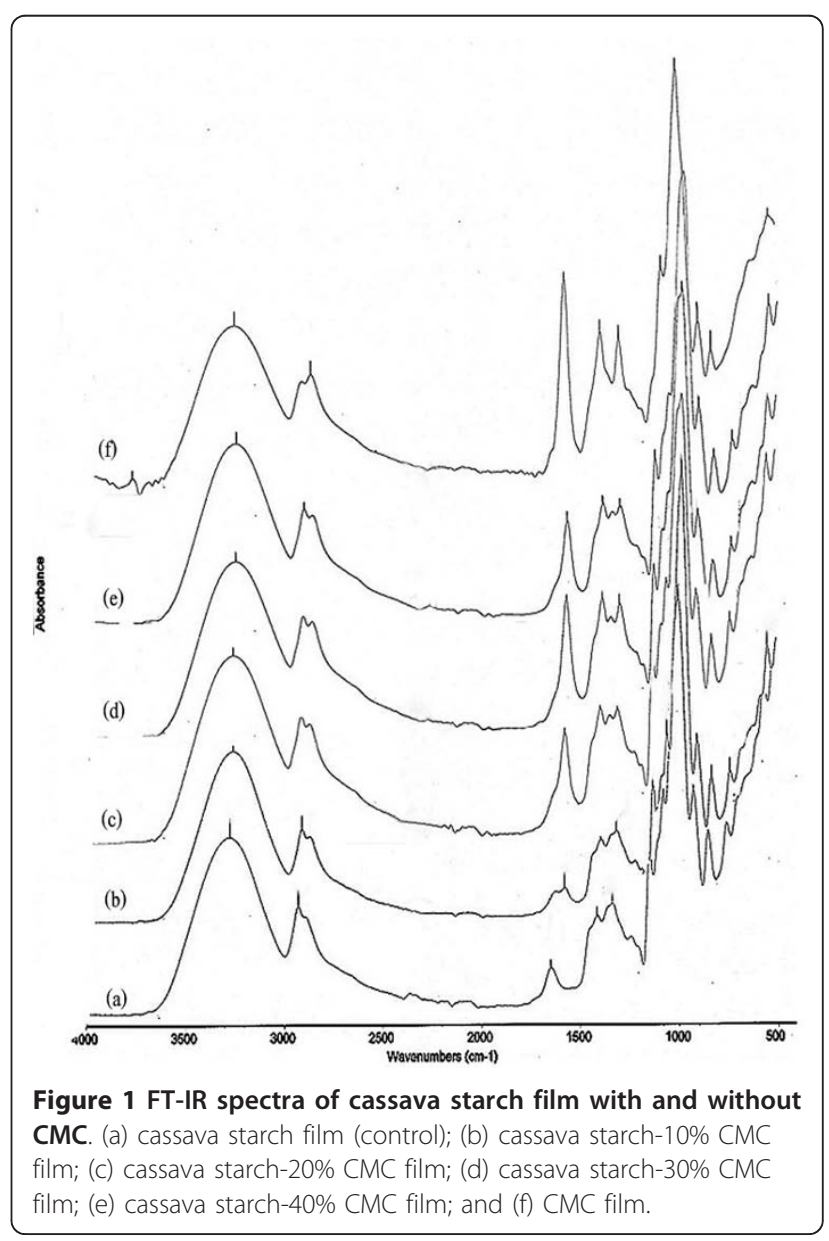


stretching vibration. The bands around 1412 and 1319 $\mathrm{cm}^{-1}$ are assigned to $-\mathrm{CH}_{2}$ scissoring and $-\mathrm{OH}$ bending vibration, respectively. The band at $1060 \mathrm{~cm}^{-1}$ is due to $\mathrm{CH}-\mathrm{O}-\mathrm{CH}_{2}$ stretching [11]. Spectra of CMC films showed peaks around $1592 \mathrm{~cm}^{-1}$, attributable to antisymmetric vibration of $\mathrm{COO}^{-}$groups [21,22].

Adding a range of CMC concentrations to cassava starch films resulted in similar characteristics in the FT-IR spectra (Figures 1b, c, d and 1e). Blending CMC with cassava starch caused minimal shifting but increased absorption in the $\mathrm{COO}^{-}$band around 1592 $\mathrm{cm}^{-1}$ in cassava starch films containing $10,20,30$ and $40 \% \mathrm{CMC}$, respectively. This indicated that the antisymmetric and symmetric vibrations of $\mathrm{C}=\mathrm{O}$ and $\mathrm{C}-\mathrm{O}$ bonds were enhanced, probably due to the disruption of intermolecular $\mathrm{H}$-bonds between carboxylic groups caused by added starch [23]. The symmetric $\mathrm{COO}^{-}$ stretching was found at $\sim 1411 \mathrm{~cm}^{-1}$ in all film samples. The water absorption band of cassava starch at 1648 $\mathrm{cm}^{-1}$ disappeared upon addition of CMC. The broad band located around $3270 \mathrm{~cm}^{-1}$ appeared in all films and was caused by $\mathrm{O}-\mathrm{H}$ stretching and intermolecular/ intramolecular hydrogen bonds [23,24]. The O-H band of CMC and cassava starch occurred at 3267 and 3261, respectively. By blending cassava starch with $\mathrm{CMC}$, the $\mathrm{O}-\mathrm{H}$ band of films shifted to $3265-3272 \mathrm{~cm}^{-1}$. The band of $\mathrm{C}-\mathrm{OH}$ bending of cassava starch film that appeared at $1337 \mathrm{~cm}^{-1}$ was shifted to $1322-1333 \mathrm{~cm}^{-1}$ with CMC addition. Xu et al. [25] reported that the ester bonds were mostly formed between the hydroxyl groups in amylopectin branches of starch and carboxylic acid groups of CMC, forming a stable cross-linked structure. This is likely what occurred in the composite cassava starch CMC films studied here. These results were correlated with FT-IR spectra of rice flour-CMC blended film [10], chitosan-cassava starch-gelatin films [26], and corn starch-CMC-nanoclay biocomposite films [13].

The effects of CMC concentration and \% relative humidity $(\mathrm{RH})$ on tensile strength and elongation at break of cassava starch based films are shown in Figure 2. It was obvious that the tensile strength and elongation at break were strongly influenced by the concentration of CMC in both 34 and $54 \%$ RH conditions.

The tensile strength and elongation at break of cassava starch based films were inversely related. At 34\% RH, cassava starch based films containing CMC had significantly higher tensile strength but lower elongation at break than control films (cassava starch film without $\mathrm{CMC}$ ). As the concentration of CMC increased, the tensile strengths of films significantly increased but the elongations at break significantly decreased. These results were consistent with corn starch films [27] and pea starch films [14] which had improved tensile strength as the concentration of added CMC increased.
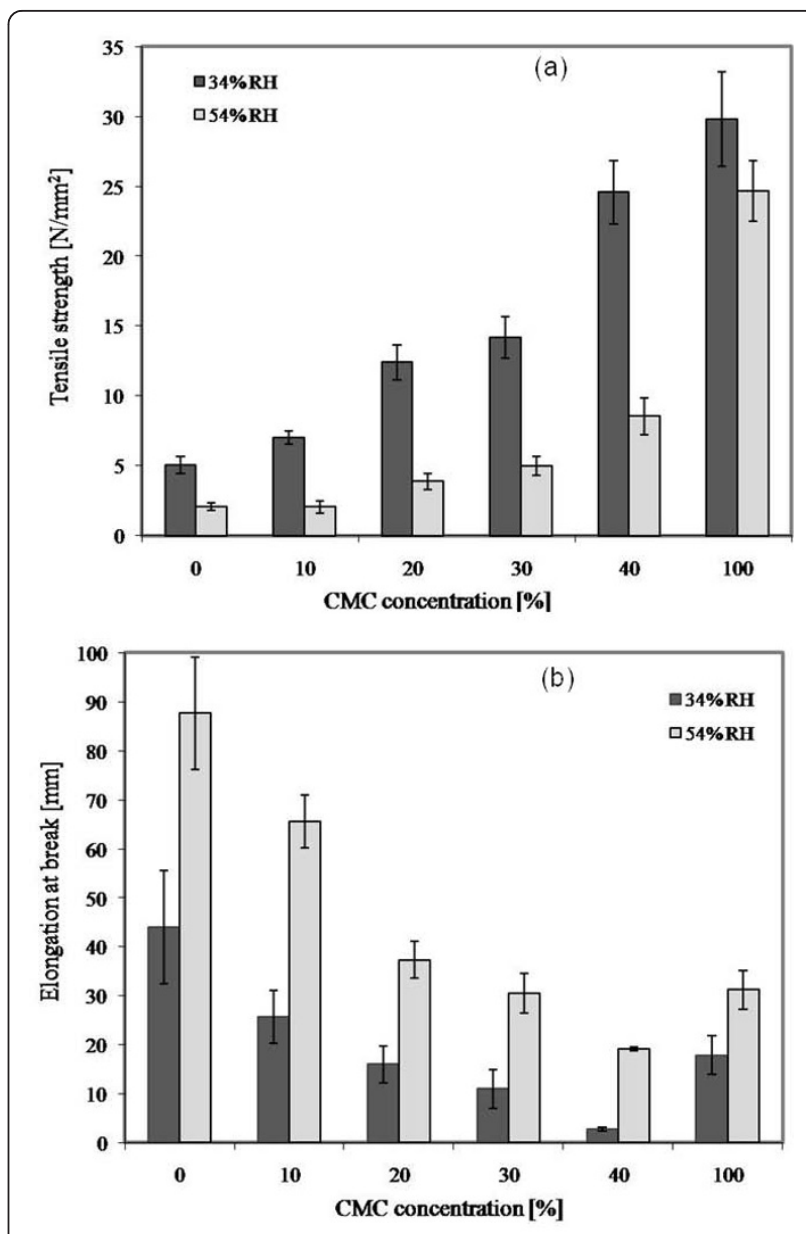

Figure 2 Effect of CMC concentrations on mechanical properties of the films. (a) tensile strength and (b) elongation at break of cassava based films at 34 and 54\% RH.

The increasing tensile strength of the cassava starch films with increasing concentrations of CMC is likely attributable to the formation of intermolecular interaction between the hydroxyl group of starch and carboxyl group of CMC [10]. During the processing and drying of the composite films, the original hydrogen bonds formed between starch molecules could be replaced by new hydrogen bonds formed between the hydroxyl groups in starch molecules and the hydroxyl and carboxyl groups in CMC [13]. Intermolecular interaction between starch and $\mathrm{CMC}$ resulted in more compact molecule structure of starch-CMC mixture, and tensile strength was therefore increased [10]. This finding corroborates the FT-IR results reported above. These results are similar to reports of the tensile strength of chitosan-starch films [25], rice starch-CMC film [10], and corn starch-CMC-nanoclay films [13]. At 54\% RH, the tensile strength of all films decreased but \% elongation increased when compared with the films at 34\% RH. Gennadios et al. [28] reported that films with 
higher elongation values usually require a lower load to cause film breakage. These results could be related to structural modification of the starch network by water which causes a greater flexibility in polymer structure. At 54\% RH, increasing CMC concentration in the cassava starch films improved the tensile strength but reduced the elongation at break. This result agreed with effect of humidity on tensile strength and \% elongation of blended chitosan-methylcellulose films [29].

Solubility in water is an important property of starchbased films. Potential applications may require water insolubility to enhance product integrity, moisture barrier properties, and shelf-life. However, in other cases the water solubility of films before product consumption might be useful, such as for the encapsulation of food ingredients or additives [30].

The water solubility of cassava starch film blends depended on the CMC concentration (Figure 3). The water solubility of the control cassava starch film was about $73 \%$, and film solubility decreased with the increase of $\mathrm{CMC}$ concentration. This result was similar to the water solubility of rice starch-CMC films [10], corn starch-CMC films [27] and corn starch-CMCnanoclay films [13]. The decreased solubility indicated that intermolecular interaction occurred between starch and CMC in the cassava starch-CMC films [10]. The hydroxyl group and carboxyl group of CMC can form strong hydrogen bonds $[27,13]$ and ester bonds [10], respectively, with the hydroxyl groups on starch, thus improving the interactions between molecules, improving the cohesiveness of the biopolymer matrix, and decreasing the water solubility [13]. The intermolecular interaction level depended on the amount of CMC and starch [10]. Besides the intermolecular interaction that

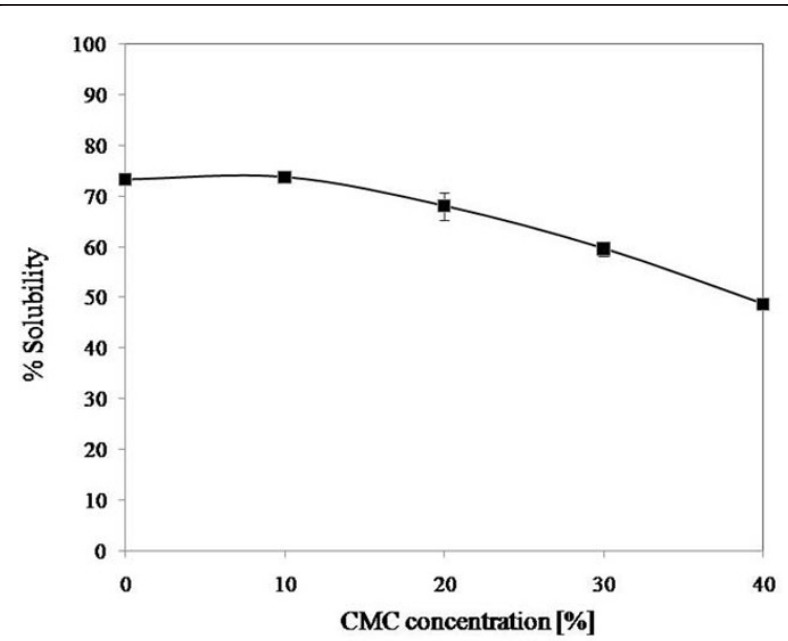

Figure 3 Effect of CMC concentration on cassava starch-CMC blended film solubility at $25^{\circ} \mathrm{C}$. occurred between starch and CMC, the decrease in water solubility as a function of CMC concentration could be due to the reduction of the starch concentration itself (as shown in Table 1) in the blended films.

The melting temperature $\left(\mathrm{T}_{\mathrm{m}}\right)$ and total heat of fusion $\left(\Delta \mathrm{H}_{\mathrm{f}}\right)$ of cassava starch films with and without $\mathrm{CMC}$ are presented in Table 2. DSC thermograms of cassava starch film, the blended films, and CMC film are shown in Figure 4. Thermograms of the films blended with CMC (Figure 4b) exhibited a single sharp endothermic peak, which indicated homogeneity of the films. This endothermic peak has been associated with the melting of crystalline starch domains reorganized during retrogradation [13]. This result agreed with DSC thermograms of pea starchCMC films [14] and corn starch-CMC-nanoclay films [13].

The melting temperature $\left(\mathrm{T}_{\mathrm{m}}\right)$ of cassava starch films blended with CMC were lower than the $T_{m}$ of cassava starch films but higher than the $\mathrm{T}_{\mathrm{m}}$ of CMC films (except for the film with $40 \% \mathrm{CMC}$ ). The $\mathrm{T}_{\mathrm{m}}$ of film blends shifted due to the interaction of the two biopolymers [31]. The area under the endothermic peak expressed the total heat of fusion of the films [32,33], which increased with increasing CMC concentrations in cassava starch films. The increased heat of fusion should be the effect of higher crystallization because of the high degree of crystallinity of CMC [34]. The total heat of fusion of blended films was lower than for $\mathrm{CMC}$ alone, likely because the interaction between cassava starch and CMC molecules interrupted the rearrangement of polymer chains [33]. Gimeno et al. [34] found that a higher interaction of hydrocolloids and starch retained more water molecules, causing a higher mobility during heating, increasing the kinetic energy, and decreasing the enthalpy value $(\Delta \mathrm{H})$. These results were similar to DSC thermograms of HDPE/PP blends [32] and chitosan-MC films with vanillin [33].

Scanning electron micrographs of cassava starch films with and without CMC were observed (Figure 5). All samples presented smooth and compact surface structures. Micrographs of cryogenic fracture surfaces of cassava starch film, cassava starch film with 30\% CMC, and CMC film obtained by SEM are shown in Figures $5 \mathrm{a}$, b and $5 \mathrm{c}$, respectively. They showed a dense and smooth cross-

Table 1 Composition of CMC/cassava starch in $100 \mathrm{ml}$ film solution

\begin{tabular}{lccc}
\hline \multirow{2}{*}{ Films } & \multicolumn{3}{c}{ Composition $\mathbf{( g / 1 0 0 ~} \mathbf{~ m l}$ water) } \\
\cline { 2 - 4 } & starch & CMC & glycerol \\
\hline Cassava starch & 5 & 0 & 1.5 \\
$10 \%$ CMC & 4.5 & 0.5 & 1.5 \\
$20 \%$ CMC & 4 & 1 & 1.5 \\
$30 \%$ CMC & 3.5 & 1.5 & 1.5 \\
$40 \%$ CMC & 3 & 2 & 1.5 \\
CMC & 0 & 5 & 1.5 \\
\hline
\end{tabular}


Table 2 Melting temperature and heat of fusion of cassava starch film without and with CMC

\begin{tabular}{lcc}
\hline Film samples & $\begin{array}{c}\mathbf{T}_{\mathbf{m}} \text { starch-CMC } \\
\text { film }\left({ }^{\circ} \mathbf{C}\right)\end{array}$ & $\begin{array}{c}\text { Heat of fusion }\left(\Delta \mathbf{H}_{\mathrm{f}}\right) \text { of } \\
\text { starch-CMC film }(\mathbf{J} / \mathbf{g})\end{array}$ \\
\hline Cassava starch: CMC (100:0) & $165.46^{\mathrm{a}}$ & $135.34^{\mathrm{a}}$ \\
Cassava starch: CMC (90:10) & $147.20^{\mathrm{a}, \mathrm{b}}$ & $91.98^{\mathrm{b}}$ \\
Cassava starch: CMC (80:20) & $144.53^{\mathrm{a}, \mathrm{b}}$ & $92.07^{\mathrm{b}}$ \\
Cassava starch: CMC (70:30) & $128.26^{\mathrm{b}}$ & $160.10^{\mathrm{a}, \mathrm{c}}$ \\
Cassava starch: CMC (60:40) & $96.62^{\mathrm{c}}$ & $173.26^{\mathrm{c}}$ \\
Cassava starch: CMC (0:100) & $102.46^{\mathrm{c}}$ & $212.98^{\mathrm{d}}$ \\
\hline
\end{tabular}

Different letters in the same column indicate significant differences between the means obtained in Duncan's test $(p<0.05$ ).

section that indicated homogeneous structure. This result was similar to the surface and cross-section morphologies of cassava starch-gum films [35] and pullulan/alginate/ CMC film [23].

\section{Conclusions}

The effects of CMC concentrations and relative humidity on physical properties of cassava starch based films were studied. The addition of CMC to the cassava starch films increased tensile strength and reduced elongation at break of the blended films. This was ascribed to the good interaction between cassava starch and CMC. FT-IR spectra indicated intermolecular interactions between cassava starch-CMC film blends by shifting of carboxyl $(\mathrm{C}=\mathrm{O})$ and $\mathrm{OH}$ groups. The thermogram of film blends also confirmed chemical interaction of cassava starch$\mathrm{CMC}$ as $\Delta \mathrm{H}$ decreases. The homogeneity of cassava starch-CMC films was represented as a single melting peak, and SEM micrographs visibly confirmed the homogeneous structure of cassava starch-CMC films. All films stored at 54\% RH gave higher elongation but lower tensile strength than films at $34 \% \mathrm{RH}$. Increasing CMC concentrations in the cassava starch film decreased water solubility of the blended films. Films containing 30\% CMC had better physical properties (high tensile strength, moderate elongation and low water solubility) than the other films. Thus, it seems that the CMC-starch biocomposite films show better physical properties than cassava starch films alone, and cassava starch-CMC composite films have the potential to be used as edible and biodegradable films for low and intermediate moisture products.

\section{Experimental}

Materials

Cassava starch (Bangkok Inter Food Co., LTD., Thailand) and glycerol (EM Science, Germany) were employed to

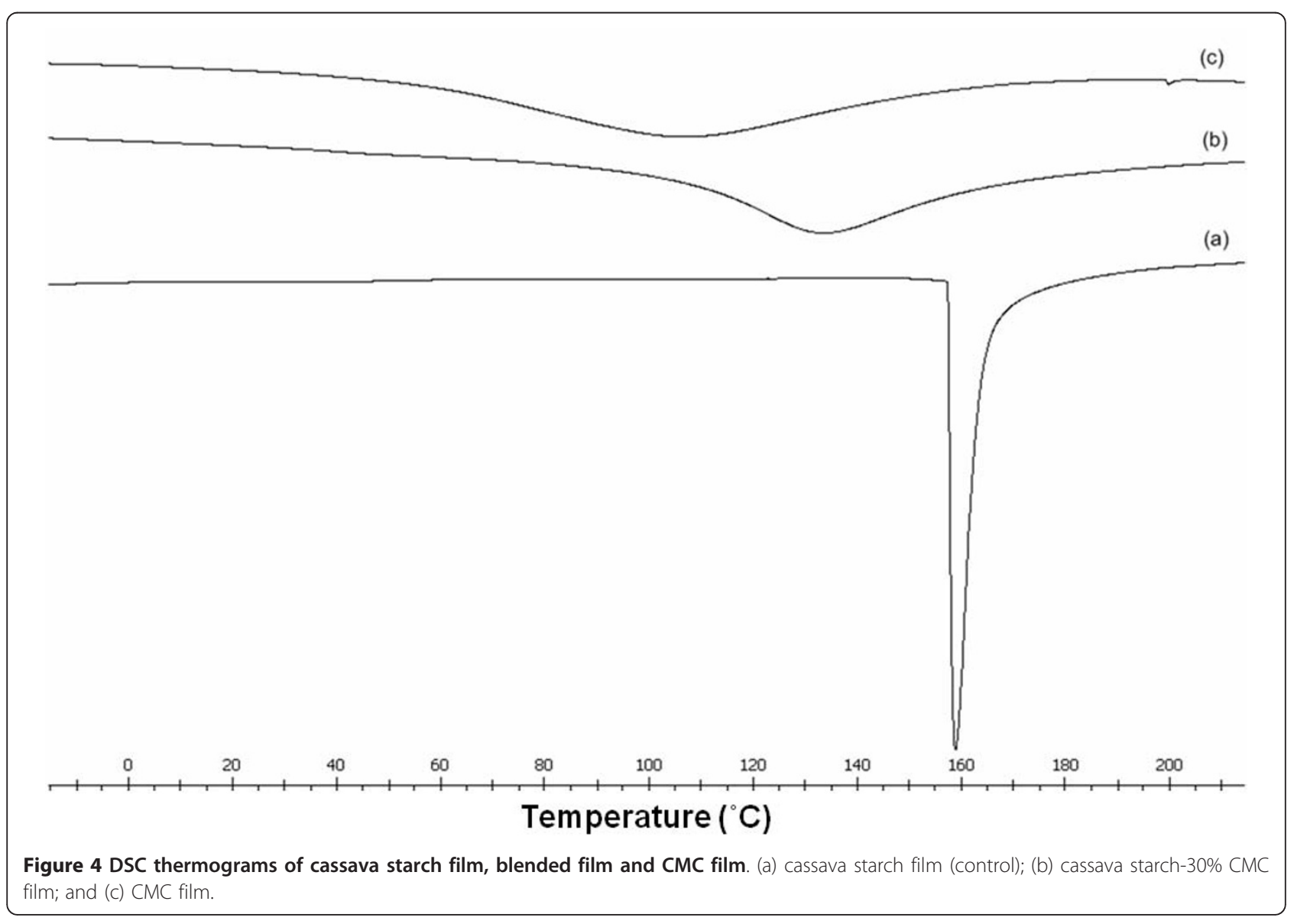




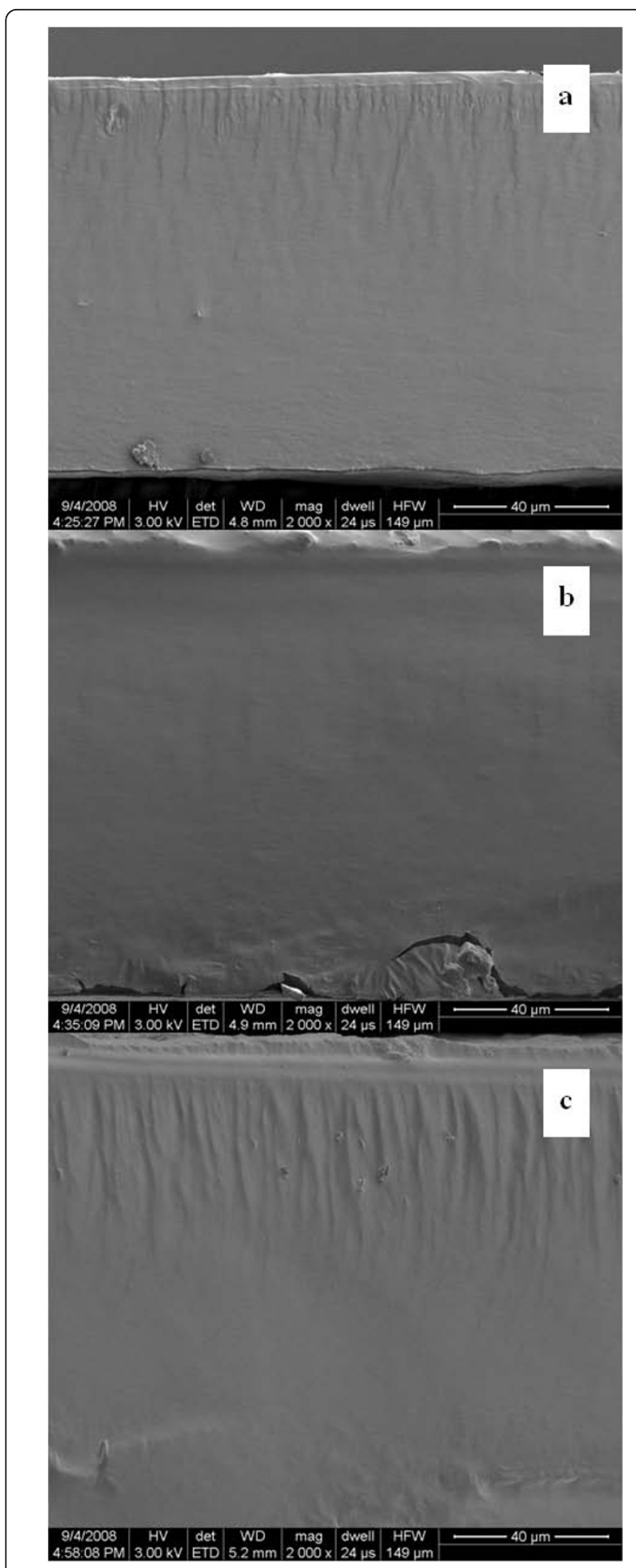

Figure 5 SEM observations of cross-sections of cassava starch film, blended film and CMC film. (a) cassava starch film (control); (b) cassava starch-30\% CMC film; and (c) CMC film at 54\% RH. produce the films. CMC was donated from Akzo Nobel (Netherlands).

\section{Cassava starch-CMC film preparation}

Solutions used to prepare films ( $5 \% \mathrm{w}$ solid/v) were prepared by dispersing cassava starch and $\mathrm{CMC}$ at different concentrations in distilled water (Table 1). Glycerol (30\% $\mathrm{w} / \mathrm{w}$ solid) was added as the plasticizer. The film solutions were heated to $80^{\circ} \mathrm{C}$ with constant stirring to obtain starch gelatinization. Then the film-forming solutions $(200 \mathrm{ml})$ were cast on flat $30 \times 30 \mathrm{~cm}$ Teflon plates. The films were dried at room temperature $\left(25^{\circ} \mathrm{C}\right)$ for 24 hours [18].

\section{Mechanical characterization}

Films were cut into $25 \times 100 \mathrm{~mm}$ strips and then equilibrated in desiccators over saturated salt solutions having the desired relative humidity $34 \%\left(\mathrm{MgCl}_{2}\right)$ and $54 \% \mathrm{RH}$ $\left(\mathrm{Mg}\left(\mathrm{NO}_{3}\right)_{2}\right)$ condition at $25^{\circ} \mathrm{C}$ for 48 hours before testing. The tensile strength and elongation at break of the films were measured using a universal testing machine (Hounsfield, England) according to the ASTM D 882-91 method [36]. The initial gauge length was $50 \mathrm{~mm}$ and crosshead speed was $50 \mathrm{~mm} / \mathrm{min}$. Ten specimens were tested for each sample.

\section{Water solubility of cassava starch-CMC films}

Film solubility in water was measured as percentage of dry matter of the film solubilized in water during a 24 hours period. This method was adapted from method of Phan et al. [37]. The initial dry matter of each film was obtained after drying film specimens at $65^{\circ} \mathrm{C}$ for 24 hours followed by placement in $0 \% \mathrm{RH}$ silica gel desiccators for 2 days. Dried films (about $0.3 \mathrm{~g}$ ) were weighed (initial dry weight) and immersed in beakers containing $50 \mathrm{ml}$ distilled water at $23^{\circ} \mathrm{C}$ that were then sealed and periodically agitated for 24 hours. The solutions containing film residues were filtered with Whatman filter paper No.1 (previously dried at $105^{\circ} \mathrm{C}$ for 24 hours and weighed before using), the filters were dried at $80^{\circ} \mathrm{C}$ for 24 hours, and the dried filters with film residues were weighed to determine the weight of dry matter (final dry weight). Tests were performed in triplicate, and the solubility was calculated using Equation (1):

$$
\text { solubility }(\%)=\left(\frac{\text { initial dried weight }- \text { final dried weight }}{\text { initial dried weight }}\right) \times 100
$$

\section{Fourier transform infrared spectroscopy (FT-IR)}

Transmission infrared spectra of the films were recorded at room temperature using a Nicolet 6700 FT-IR spectrometer (Thermo Electron Corporation, USA) in the range of $4000-400 \mathrm{~cm}^{-1}$ with 64 scans, $4 \mathrm{~cm}^{-1}$ resolution, 
using a DTGS $\mathrm{KBr}$ detector and $\mathrm{KBr}$ beam splitter. The films were mounted directly in the sample holder.

\section{Differential scanning calorimetry (DSC)}

Differential scanning calorimetry was carried out using a Mettler Toledo Schwerzenbach instrument (USA). Samples were previously conditioned at $54 \% \mathrm{RH}$ and $25^{\circ} \mathrm{C}$. Three replicates of film samples ( 10 milligrams) contained in aluminum pans were heated in the temperature range -20 to $220^{\circ} \mathrm{C}$ at a heating rate of $5^{\circ} \mathrm{C} / \mathrm{min}$ in a nitrogen atmosphere $(50 \mathrm{ml} / \mathrm{min})$.

\section{Film morphology}

Film samples were conditioned at $25^{\circ} \mathrm{C}$ in $54 \% \mathrm{RH}$ desiccators for 7 days prior to analysis. The surface and cross-section microstructure of films were observed by Field-Emission Scanning Electron Microscope (FESEM, JOEL JSM-6700F, Japan).

\section{Statistical analysis}

ANOVA analysis was performed on all results using a statistical program SPSS v. 10.0 at a confidence interval of $95 \%$ to determine the significant difference between group samples.

\section{Acknowledgements \\ The authors gratefully acknowledge the National Research University Project under Thailand's Office of the Higher Education Commission (CHE), Thailand for financial support. The authors also thank Akzo Nobel (Netherlands) for CMC donation.}

\section{Author details \\ 'Division of Biotechnology, Graduate School, Chiang Mai University, Chiang Mai 50200, Thailand. ${ }^{2}$ Whistler Center for Carbohydrate Research, Department of Food Science, Purdue University, West Lafayette, IN 47907 , USA. ${ }^{3}$ Division of Biotechnology, Faculty of Agro-Industry, Chiang Mai University, Chiang Mai 50100, Thailand. ${ }^{4}$ Department of Chemistry, Faculty of Science, Chiang Mai University, Chiang Mai 50200, Thailand. ${ }^{5}$ Division of Packaging Technology, Faculty of Agro-Industry, Chiang Mai University, Chiang Mai 50100, Thailand. 'Materials Science Research Center, Faculty of Science, Chiang Mai University, 50200, Thailand.}

\section{Authors' contributions}

WT carried out the study design, film preparation, testing, performed the statistical analysis and drafted the manuscript. LJM has been involved in revising for important intellectual content and structure of manuscript. SW and PS have given final approval of the version to be published. PR has made substantial contributions to conception and design, analysis and interpretation of data, revises for important intellectual content and coordination and has given final approval of the version to be published. All authors read and approved the final manuscript.

\section{Competing interests}

The authors declare that they have no competing interests.

Received: 16 September 2010 Accepted: 10 February 2011 Published: 10 February 2011

\section{References}

1. Ou S, Wang Y, Tang S, Huang C, Jackson MG: Role of ferulic acid in preparing edible films from soy protein isolate. J Food Eng 2005, 70:205-210.
2. Banker GS: Film coating theory and practice. J Pharm Sci 1966, 55:81-89.

3. Krochta JM, De Mulder CLC: Biodegradable polymers from agricultural products. In Agricultural Materials as Renewable Resources. Edited by: Fuller G, McKeon TA, Bills DD. Washington, DC.: American Chemical Society; 1995:120-140.

4. Bangyekan C, Aht-Ong D, Srikulkit K: Preparation and properties evaluation of chitosan-coated cassava starch films. Carbohydr Polym 2006, 63:61-71.

5. Suppakul P, Chalernsook B, Ratisuthawat B, Prapasitthi S, Munchukangwan K: Plasticizer and Relative Humidity Effects on Mechanical Properties of Cassava Flour Films. The 15th IAPRI World Conference on Packaging; 3 - 5 October 2006 Tokyo, Japan 2006.

6. Rindlav-Westling A, Stading M, Hermansson AM, Gatenholm P: Structure, mechanical and barrier properties of amylose and amylopectin films. Carbohyd Polym 1998, 36:217-224.

7. Kester JJ, Fennema O: Edible films and coatings: a review. Food Technol 1986, 40:47-59.

8. Chandra R, Rustgi R: Biodegradable polymers. Prog Polym Sci 1998, 23:1273-1335.

9. Coffin DR, Fishman ML: Viscoelastic properties of pectin/starch blends. J Agr Food Chem 1993, 41:1192-1197.

10. Li Y, Shoemaker CF, Ma J, Shen X, Zhong F: Paste viscosity of rice starches of different amylose content and carboxymethylcellulose formed by dry heating and the physical properties of their films. Food Chem 2008, 109:616-623.

11. Biswal DR, Singh RP: Characterisation of carboxymethyl cellulose and polyacrylamide graft copolymer. Carbohyd Polym 2004, 57:379-387.

12. Nie H, Liu M, Zhan F, Guo M: Factors on the preparation of carboxymethycellulose hydrogel and its degradation behaviour in soil. Carbohyd Polym 2004, 58:185-189.

13. Almasi H, Ghanbarzadeh B, Entezami AA: Physicochemical properties of starch-CMC-nanoclay biodegradable films. Biol Macromol 2010, 46:1-5.

14. Ma X, Chang PR, Yu J: Properties of biodegradable thermoplastic pea starch/carboxymethyl cellulose and pea starch/microcrystalline cellulose composites. Carbohyd Polym 2008, 72:369-375.

15. Arvanitoyannis I, Biliaderis CG: Physical properties of polyol-plasticized edible blends made of methyl cellulose and soluble starch. Carbohyd Polym 1999, 38:47-58.

16. Biliaderis CG, Lazaridou A, Arvanitoyannis I: Glass transition and physical properties of polyol-plasticised pullulan-starch blends at low moisture. Carbohyd Polym 1999, 40:29-47.

17. Lazaridou A, Biliaderis CG: Thermophysical properties of chitosan, chitosan-starch and chitosan-pullulan films near the glass transition. Carbohyd Polym 2002, 48:179-190.

18. Tongdeesoontorn W, Mauer $L$, Wongruong S, Rachtanapun P: Water vapour permeability and sorption isotherm of cassava starch based films blended with gelatin and carboxymethyl cellulose. Asian J Food Agro-Ind 2009, 2:501-514

19. Vicentini NM, Dupuy N, Leitzelman M, Cereda MP, Sobral PJA: Prediction of cassava starch eible film properties by chemometric analysis of infrared spectra. Spectrosc Lett 2005, 38:749-767.

20. Su JF, Huang Z, Yuan XY, Wang XY, Li M: Structure and properties of carboxymethyl cellulose/soy protein isolate blend edible films crosslinked by Maillard reactions. Carbohyd Polym 2010, 79:145-153.

21. Xiao C, Weng L, Zhang L: Improvement of physical properties of crosslinked alginate and carboxymethyl konjac glucomannan blend films. J App Polym Sci 2002, 84:2554-2560.

22. Yang F, Li G, He YG, Ren FX, Wang Gx: Synthesis, characterization, and applied properties of carboxymethyl cellulose and polyacrylamide graft copolymer. Carbohyd Polym 2009, 78:95-99.

23. Tong $Q$, Xiao Q, Lim LT: Preparation and properties of pullulan-alginatecarboxymethylcellulose blend films. Food Res Int 2008, 41:1007-1014.

24. Jiang L, Li Y, Wang X, Zhang L, Wen J, Gong M: Preparation and properties of nano-hydroxyapatite/chitosan/carboxymethyl cellulose composite scaffold. Carbohyd Polym 2008, 74:680-684.

25. Xu YX, Kim KM, Hanna MA, Nag D: Chitosan-starch composite film: preparation and characterization. Ind Crop Prod 2005, 21:185-192.

26. Zhong QP, Xia WS: Physicochemical properties of edible and preservative films from chitosan/cassava starch/gelatin blend plasticized with glycerol. Food Technol Biotechnol 2008, 46:262-269. 
27. Ghanbarzadeh B, Almasi H, Entezami AA: Physical properties of edible modified starch/carboxymethyl cellulose films. Innov Food Sci Emerg 2010, 11:697-702.

28. Gennadios A, Weller CL, Testin RF: Property modification of edible wheat gluten films. Trans ASAE 1993, 36:465-470.

29. Rachtanapun $P$, Wongchaiya $P$ : Effect of relative humidity on mechanical properties on blended chitosan-methylcellulose film. Mae Fah Luang Symposium; 26-28 Nov Chiang Rai, Thailand 2008, 50.

30. Bertuzzi MA, Castro Vidaurre EF, Armada M, Gottifredi JC: Water vapor permeability of edible starch based films. J Food Eng 2007, 80:972-978.

31. Veiga-Santos P, Oliveira LM, Cereda MP, Scamparini ARP: Sucrose and inverted sugar as plasticizer. Effect on cassava starch-gelatin film mechanical properties, hydrophilicity and water activity. Food Chem 2007, 103:255-262

32. Rachtanapun P, Selke SEM, Matuana LM: Effect of the high-density polyethylene melt index on the microcellular foaming of high-density polyethylene/polypropylene blends. J Appl Polym Sci 2004, 93:364-371.

33. Sangsuwan J, Rattanapanone N, Rachtanapun P: Effect of vanillin and plasticizer on properties of chitosan-methyl cellulose based film. J Appl Polym Sci 2008, 109:3540-3545.

34. Gimeno E, Moraru Cl, Kokini JL: Effect of xanthan gum and CMC on the structure and texture of corn flour pellets expanded by microwave heating. Cereal Chem 2004, 81:100-107.

35. ASTM International: Standard test methods for tensile properties of thin plastic sheeting. Annual book of ASTM Philadelphia: American Society for Testing and Materials, D882-91; 1991.

36. Phan TD, Debeaufort F, Luu D, Voilley A: Functional properties of edible agar-based and starch-based films for food quality preservation. J Agr Food Chem 2005, 53:973-981.

37. Veiga-Santos P, Suzuki CK, Cereda MP, Scamparini ARP: Microstructure and color of starch-gum films: Effect of gum deacetylation and additives. Part 2. Food Hydrocolloid 2005, 19:1064-1073.

doi:10.1186/1752-153X-5-6

Cite this article as: Tongdeesoontorn et al:: Effect of carboxymethyl cellulose concentration on physical properties of biodegradable cassava starch-based films. Chemistry Central Journal 2011 5:6.

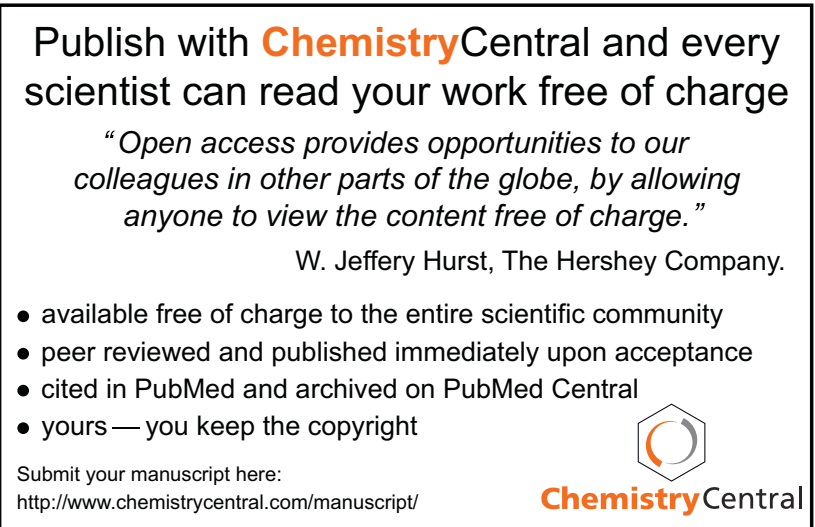

